\title{
Characterization of Sterol Demethylation Inhibitor-Resistant Isolates of Fusarium asiaticum and $F$. graminearum Collected from Wheat in China
}

\author{
Y. Yin, X. Liu, B. Li, and Z. Ma
}

Institute of Biotechnology, Zhejiang University, Hangzhou 310029, China.

Accepted for publication 31 December 2008.

\begin{abstract}
Yin, Y., Liu, X., Li, B., and Ma, Z. 2009. Characterization of sterol demethylation inhibitor-resistant isolates of Fusarium asiaticum and $F$. graminearum collected from wheat in China. Phytopathology 99:487497.

Fusarium asiaticum and F. graminearum are the primary causal agents of Fusarium head blight (FHB) of wheat in China. In this study, sensitivities of $159 \mathrm{~F}$. asiaticum and F. graminearum isolates to a benzimidazole fungicide carbendazim (MBC) and to sterol demethylation inhibitors (DMIs) tebuconazole and prochloraz were determined. Among the 159 isolates, 9 were resistant to MBC and designated as MBC-R isolates. Three showed resistance to tebuconazole and prochloraz and designated as DMI-R isolates. There was no cross-resistance between MBC and DMI. Genetic analysis by microsatellite-primed polymerase chain reaction (PCR) showed that MBC-R or DMI-R isolates had different genotypes, which indicated that they originated from different wild-type
\end{abstract}

ABSTRACT

Fusarium head blight (FHB) is a devastating disease of cereal crops which can cause huge losses in epidemic years. In addition to the yield loss caused by the disease, the contamination of infected grains with mycotoxins poses a serious threat to human and animal health. Although a number of Fusarium spp. can cause FHB, the primary etiological agents of this disease belong to the Fusarium graminearum species complex of B-trichothecene toxin producers, which contain at least 11 phylogenetic species, including $F$. acaciae-mearnsii, F. asiaticum, $F$. austroamericanum, $F$. boothii, $F$. brasilicum, F. cortaderiae, F. gerlachii, $F$. graminearum, $F$. meridionale, $F$. mesoamericanum, and $F$. vorosii, (11,32,34). Different Fusarium spp. may be associated with FHB in different regions of the world because of different cropping systems and climatic conditions $(28,36)$. In China, $F$. asiaticum and $F$. graminearum are the major causal agents of FHB, although other Fusarium spp. (such as F. culmorum, F. avenaceum, and $F$. tricinctum) were also isolated occasionally from infected wheat heads (7). F. asiaticum isolates are able to produce deoxynivalenol, 3-acetyldeoxynivalenol (3-AcDON), 15acetyldeoxynivalenol (15-AcDON), nivalenol, and 4-acetylnivalenol (NIV) mycotoxins. However, F. graminearum isolates produce only $15-\mathrm{AcDON}$ and do not produce $3-\mathrm{AcDON}$ or NIV (37). The difference between $F$. asiaticum and $F$. graminearum that produce $15-\mathrm{AcDON}$ is the presence or absence of 11-bp repeats within the sequence of a trichothecene biosynthesis gene Tri7. The 11-bp repeats are present in $F$. graminearum but absent in $F$. asiaticum (37). 15-AcDON chemotype carrying the 11-bp repeats belongs to $F$. graminearum, whereas the same chemotype

Corresponding author: Z. Ma; E-mail address: zhma@zju.edu.cn

doi:10.1094/PHYTO-99-5-0487

(C) 2009 The American Phytopathological Society parents. Analysis of two $14 \alpha$-demethylase (cyp51) homologous genes (cyp51A and cyp51B) showed that the $F$. asiaticum isolates could be distinguished from $F$. graminearum isolates based on the sequence of cyp51A. Analysis of deduced amino acid sequence of cyp51A and cyp51B suggested that no mutations were associated with DMI resistance. Realtime PCR analysis showed that the DMI resistance was not related to the expression of cyp51A and cyp51B in $F$. asiaticum and $F$. graminearum, but expressions of both genes were induced greatly by the tebuconazole. Results of this study indicated that cyp51A would be an informative marker for analysis of population structure of $F$. asiaticum and $F$. graminearum, and the existence of homologous cyp51 genes in $F$. asiaticum and $F$. graminearum could provide new insights into DMI resistance in phytopathogenic fungi.

Additional keyword: azole.

lacking the 11-bp repeats is of $F$. asiaticum $(14,29,37)$. Zhang et al. (37) analyzed 299 isolates collected from various epidemic regions of China and found that 231 isolates $(77.3 \%$ ) belonged to $F$. asiaticum and the remaining 68 isolates were $F$. graminearum. These two species are also predominant in the populations of FHB pathogens in Japan (33).

Currently, most wheat cultivars planted in the world are susceptible to $F$. graminearum complex; therefore, one primary method for management of FHB is through the application of fungicides during wheat anthesis, the time of primary infection. In China, the benzimidazole fungicides, particularly carbendazim (MBC), have been used extensively for the control of FHB since the early 1970s. Because of the heavy application of benzimidazole fungicides, resistance of $F$. graminearum complex to MBC has been detected since 1992, and a decline in the control of FHB with MBC has been observed in some areas since 1998 $(5,35,38)$. Alternative applications of MBC with other fungicides, therefore, would be necessary in management of MBC resistance in FHB.

The sterol demethylation inhibitor (DMI) fungicides inhibit the sterol C-14 $\alpha$-demethylation of 24-methylenedihydrolanosterol, a precursor of ergosterol in fungi (4). DMIs comprise a large number of commercially successful fungicides and were first used agriculturally in the 1970s. Many field studies showed that DMI fungicides, such as tebuconazole and prochloraz, are practically effective against Fusarium spp. $(25,26)$. Although declining sensitivity to DMI in FHB pathogens has not caused a problem in the field yet (13), DMI resistance has developed in the populations of several important phytopathogenic fungi, including Blumeriella jaapii (22), Erysiphe graminis (9), Monilinia fructicola (18), and Mycosphaerella graminicola (15), which indicated that it is necessary to incorporate effective antiresistance strategies in management of FHB with DMIs. 
Molecular mechanisms of DMI resistance in fungi have been investigated intensively. Common mechanisms of DMI resistance include (i) mutations in the DMI target enzyme, $14 \alpha$-demethylase (CYP51), encoded by the cyp51 gene; (ii) overexpression of the cyp51 gene; and (iii) overexpression of ATP-binding cassette (ABC) transporter genes encoding efflux pumps $(10,16,20,30,31)$. To date, resistance of $F$. asiaticum or $F$. graminearum to DMI fungicides has not been documented. Thus, the major objectives of this study were to (i) determine sensitivity to DMI fungicides tebuconazole and prochloraz in $F$. asiaticum and $F$. graminearum collected from wheat in China and (ii) investigate possible mechanisms of DMI resistance in $F$. asiaticum and $F$. graminearum.

\section{MATERIALS AND METHODS}

Determination of $F$. asiaticum and $F$. graminearum sensitivity to MBC, tebuconazole, and prochloraz. In total, 159 single-spore isolates of $F$. asiaticum and $F$. graminearum (118 F. asiaticum and $41 F$. graminearum isolates) used in this study were collected from infected wheat heads in 2007 and 2008 at different locations, where tebuconazole and prochloraz have never been used but MBC and triadimefon have been used for more than 20 years (Table 1). In these locations, tradimefon was used for the control of wheat powdery mildew. The isolates were recovered from individual infected wheat heads and no more than four isolates were collected from each sampled field. $F$. asiaticum and $F$. graminearum were identified based on the presence or absence of 11-bp repeats within the Tri7 gene detected with the primer pair GzTri7f1/r1 (Table 2) using a previously published protocol $(14,37)$.

MBC (25\% active ingredient [a.i.]) (GuoGuang Agricultural Chemical Co. Ltd., Sichuan, China) was dissolved in sterilized water, adjusted to a concentration of $100 \mathrm{mg} / \mathrm{ml}$, and added to potato dextrose agar (PDA) medium after sterilization to produce final concentrations of $0,10,50,100$, and $500 \mu \mathrm{g} / \mathrm{ml}$. The concentrations were chosen according to a previous study (5). Technical tebuconazole (97.9\% a.i.) (Shanghai Agricultural Chemical Co. Ltd., Shanghai, China) was dissolved in acetone at a concentration of $100 \mathrm{mg} / \mathrm{ml}$ and added to PDA medium after sterilization to produce final concentrations of $0,0.175,0.35,0.7,1.4,2.8,5.6$, and $11.2 \mu \mathrm{g} / \mathrm{ml}$. Prochloraz (95\% a.i.) (QingFeng Agricultural Chemical Co. Ltd., Zhejiang, China) was dissolved in acetone, adjusted to a concentration of $100 \mathrm{mg} / \mathrm{ml}$, and added to PDA to produce final concentrations of $0,0.01,0.03,0.1,0.3,1.0,3.0$, and $9.0 \mu \mathrm{g} / \mathrm{ml}$.

To determine sensitivity of $F$. asiaticum and $F$. graminearum to $\mathrm{MBC}$, a $5-\mathrm{mm}$ mycelial plug was taken from the edge of a 3-day-old colony and placed on the center of a PDA plate amended with MBC at each of the above concentrations. Three replicate plates for each concentration were used for each isolate. After the plates were incubated at $25^{\circ} \mathrm{C}$ for 5 days in the dark, the mycelial growth was recorded for each plate. The experiment was repeated three times.

To determine sensitivity of $F$. asiaticum and $F$. graminearum to tebuconazole and prochloraz, a 5-mm mycelial plug was taken from the edge of a 3-day-old colony and placed on the center of a PDA plate amended with tebuconazole or prochloraz at each of the above concentrations. Two replicates for each concentration were used for each isolate. After incubation at $25^{\circ} \mathrm{C}$ for 3 days, colony diameter in each plate was measured in two perpendicular directions with the original mycelial plug diameter $(5 \mathrm{~mm})$ subtracted from each measurement. For each plate, the average of the colony diameters was used for calculating the fungicide concentration that results in 50\% mycelial growth inhibition $\left(\mathrm{EC}_{50}\right)$. The $\mathrm{EC}_{50}$ values were calculated with the Data Processing System (DPS) computer program (Hangzhou Reifeng Information Technology Ltd., Hangzhou, China). The experiment was per- formed twice. Because the two experiments did not differ significantly $(P>0.05$, Fisher's least significant difference test $)$, the average $\mathrm{EC}_{50}$ values from the two experiments for each isolate were used in the data analysis.

Genetic relationships among the MBC-resistant and DMIresistant isolates. In order to investigate genetic relationships among the MBC-resistant (MBC-R) or DMI-resistant (DMI-R) isolates, all 9 MBC-R, 3 DMI-R, and 27 sensitive isolates were analyzed by microsatellite-primed polymerase chain reaction (MP-PCR) with three microsatellite primers: $(\mathrm{AAC})_{5},(\mathrm{GACA})_{4}$, and M13 (Table 2). These three primers were chosen because they were informative in previous studies for Botryosphaeria dothidea (19) and Botrytis cinerea (21). PCR amplifications were performed in a $25-\mu \mathrm{l}$ volume containing $20 \mathrm{ng}$ of fungal genomic DNA, $0.2 \mu \mathrm{M}$ each primer, $0.2 \mathrm{mM}$ each of dNTP, $2.0 \mathrm{mM}$ $\mathrm{MgCl}_{2}, 1 \times$ Promega Taq polymerase buffer (10 mM Tris- $\mathrm{HCl}, \mathrm{pH}$ 9.0; $50 \mathrm{mM} \mathrm{KCl}$; and $0.1 \%$ Triton $\mathrm{X}-100)$, and 2 units of Taq polymerase (Shanghai Promega Corp., Shanghai, China). The PCR amplifications were performed in a PTC-200 DNA Engine Cycler (MJ Research, Waltham, MA, USA) set to the following parameters: an initial preheat for $3 \mathrm{~min}$ at $95^{\circ} \mathrm{C}$; followed by 30 cycles of denaturation at $94^{\circ} \mathrm{C}$ for $1 \mathrm{~min}$, annealing at $45^{\circ} \mathrm{C}$ for $1 \mathrm{~min}$, and extension at $72^{\circ} \mathrm{C}$ for $1.5 \mathrm{~min}$; and terminated with a final extension at $72^{\circ} \mathrm{C}$ for $10 \mathrm{~min}$. Each isolate was amplified twice. The PCR products were separated on $1.5 \%$ agarose gels in $1 \times$ Tris-acetate (TAE) buffer and photographed after staining with ethidium bromide.

To analyze MP-PCR data, each isolate was scored for the presence or absence of each amplicon using Gel-Pro System (Media Cybernmetics Inc., Bethesda, MD). Genetic similarities (S) were calculated using a simple matching coefficient. A phenogram was constructed using the unweighted pair group method with arithmetic average (UPGMA) by the program Sequential, Agglomerative, Hierarchical, and Nested clustering methods (SAHN) of the software package NTSYS-pc 2.1 (Department of Ecology and Evolution, State University of New York).

Analysis of DNA sequence of cyp51 genes from DMIsensitive and DMI-R isolates. To investigate possible mechanisms of $F$. asiaticum and $F$. graminearum resistance to DMIs, DNA sequences of cyp51 genes from three DMI-R (JS3, JS6, and HN8) and two DMI-sensitive (DMI-S) isolates (HB3 and NX3) were analyzed. The search for cyp51 in the genome database of $F$. graminearum showed that there were three putative cyp51 genes, designated as cyp51A, cyp51B, and cyp51C. Based on the sequences deposited on the genome database of $F$. graminearum at Broad Institute (available online), the primer pairs F51A-F + F51A-R, F51B-F + F51B-R, and F51C-F1 + F51C-R1 (Table 2) were designed to amplify the full sequence of cyp51A, cyp51B, and cyp51C, respectively. PCR amplifications were performed using the following parameters: initial preheat for $3 \mathrm{~min}$ at $95^{\circ} \mathrm{C}$; followed by 35 cycles of $94^{\circ} \mathrm{C}$ for $1 \mathrm{~min}, 53^{\circ} \mathrm{C}$ for $30 \mathrm{~s}$, and $72^{\circ} \mathrm{C}$ for $1 \mathrm{~min}$; and a final extension at $72^{\circ} \mathrm{C}$ for $5 \mathrm{~min}$. The PCR product from each isolate was purified, cloned, and sequenced. The experiment was conducted independently twice for each isolate to avoid mismatch sequences during PCR amplification and sequencing. The sequences were deposited into GenBank under accession numbers FJ216393 to FJ216402.

Analysis of expression of cyp51 genes in DMI-R and DMI-S isolates. To determine possible differences in expression of cyp51 genes between DMI-R and DMI-S isolates, each of DMI-R isolates JS3, JS6, and HN8 and DMI-S isolates HB3 and HE-3 was cultured in potato dextrose broth (PDB) medium for 4 days. Before mycelia were harvested for RNA extraction, each isolate was treated with tebuconazole at $2.5 \mu \mathrm{g} / \mathrm{ml}$ for $6 \mathrm{~h}$. The untreated mycelia of each isolate were used as the control. RNA from mycelia of each isolate was extracted using a TaKaRa RNAiso Reagent (TaKaRa Biotech. Co., Dalian, China) according to the manufacturer's instructions. Briefly, fresh mycelia of each sample 


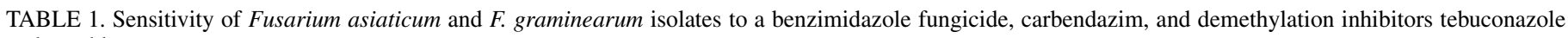
and prochloraz

\begin{tabular}{|c|c|c|c|c|c|}
\hline \multirow[b]{2}{*}{ Isolate } & \multirow[b]{2}{*}{ Year of isolation } & \multirow[b]{2}{*}{ Origin (city, province) } & \multicolumn{2}{|c|}{$\mathrm{EC}_{50}(\mu \mathrm{g} / \mathrm{ml})^{\mathrm{a}}$} & \multirow[b]{2}{*}{ Sensitivity to carbendazim ${ }^{\mathrm{b}}$} \\
\hline & & & Tebuconazole & Prochloraz & \\
\hline \multicolumn{6}{|c|}{ F. asiaticum } \\
\hline JS1 & 2007 & Zhenjiang, Jiangsu & 0.770 & 0.040 & MBC-S \\
\hline JS2 & 2007 & Zheniiang, Jiangsu & 0.297 & 0.060 & MBC-S \\
\hline JS3 & 2007 & Zhenjiang, Jiangsu & 4.152 & 1.467 & MBC-S \\
\hline JS4 & 2007 & Zhenjiang, Jiangsu & 0.109 & 0.020 & MBC-S \\
\hline JS5 & 2007 & Yangzhou, Jiangsu & 0.126 & 0.013 & MBC-S \\
\hline JS6 & 2007 & Yangzhou, Jiangsu & 4.517 & 2.888 & MBC-S \\
\hline JS7 & 2007 & Yangzhou, Jiangsu & 0.124 & 0.035 & MBC-S \\
\hline JS8 & 2007 & Yangzhou, Jiangsu & 0.097 & 0.036 & MBC-S \\
\hline JS9 & 2007 & Yangzhou, Jiangsu & 0.085 & 0.029 & MBC-S \\
\hline JS10 & 2008 & Huai'an, Jiangsu & 0.064 & 0.071 & MBC-S \\
\hline JS11 & 2008 & Huai'an, Jiangsu & 1.236 & 0.154 & MBC-S \\
\hline JS12 & 2008 & Huai'an, Jiangsu & 0.460 & 0.032 & MBC-S \\
\hline JS13 & 2008 & Huai'an Jiangsu & 0.938 & 0.021 & MBC-S \\
\hline JS14 & 2007 & Lianyungang, Jiangsu & 0.254 & 0.027 & MBC-S \\
\hline JS15 & 2007 & Lianyungang, Jiangsu & 0.064 & 0.036 & MBC-S \\
\hline JS16 & 2007 & Lianyungang, Jiangsu & 0.085 & 0.036 & MBC-S \\
\hline JS17 & 2007 & Taizhou, Jiangsu & 0.075 & 0.020 & MBC-R \\
\hline JS18 & 2007 & Taizhou, Jiangsu & 0.062 & 0.029 & MBC-R \\
\hline JS19 & 2007 & Taizhou, Jiangsu & 0.095 & 0.065 & MBC-S \\
\hline JS20 & 2007 & Taizhou, Jiangsu & 0.252 & 0.018 & MBC-S \\
\hline JS21 & 2007 & Zhangjiagang, Jiangsu & 0.202 & 0.030 & MBC-S \\
\hline JS22 & 2007 & Nanjing, Jiangsu & 0.692 & 0.047 & MBC-S \\
\hline JS23 & 2007 & Nantong, Jiangsu & 0.138 & 0.036 & MBC-S \\
\hline JS24 & 2007 & Nantong, Jiangsu & 0.089 & 0.038 & MBC-R \\
\hline JS25 & 2007 & Nantong, Jiangsu & 0.102 & 0.065 & MBC-R \\
\hline JS26 & 2007 & Nantong, Jiangsu & 0.055 & 0.031 & MBC-R \\
\hline JS27 & 2007 & Nantong, Jiangsu & 1.236 & 0.154 & MBC-R \\
\hline AH1 & 2008 & Chuzhou, Anhui & 2.111 & 0.570 & MBC-S \\
\hline AH3 & 2008 & Chuzhou, Anhui & 0.161 & 0.014 & MBC-S \\
\hline $\mathrm{AH} 4$ & 2008 & Chuzhou, Anhui & 0.161 & 0.007 & MBC-S \\
\hline AH5 & 2008 & Chuzhou, Anhui & 0.065 & 0.015 & MBC-S \\
\hline AH6 & 2008 & Chuzhou, Anhui & 0.179 & 0.017 & MBC-S \\
\hline $\mathrm{AH} 7$ & 2008 & Chuzhou, Anhui & 0.096 & 0.024 & MBC-S \\
\hline AH8 & 2008 & Chuzhou, Anhui & 0.055 & 0.015 & MBC-S \\
\hline AH9 & 2008 & Chuzhou, Anhui & 0.204 & 0.023 & MBC-S \\
\hline AH10 & 2008 & Hefei, Anhui & 0.306 & 0.025 & MBC-S \\
\hline AH11 & 2008 & Hefei, Anhui & 0.834 & 0.024 & MBC-S \\
\hline AH12 & 2008 & Hefei, Anhui & 0.527 & 0.065 & MBC-S \\
\hline AH13 & 2008 & Liu'an, Anhui & 0.032 & 0.012 & MBC-S \\
\hline AH14 & 2008 & Liu'an, Anhui & 0.016 & 0.013 & MBC-S \\
\hline AH 15 & 2008 & Liu'an, Anhui & 0.549 & 0.089 & MBC-S \\
\hline AH16 & 2008 & Fuyang, Anhui & 0.984 & 0.090 & MBC-S \\
\hline AH17 & 2008 & Suzhou, Anhui & 0.554 & 0.015 & MBC-S \\
\hline AH19 & 2008 & Ningguo, Anhui & 0.043 & 0.002 & MBC-S \\
\hline AH20 & 2008 & Ningguo, Anhui & 1.444 & 0.156 & MBC-S \\
\hline $\mathrm{AH} 21$ & 2008 & Huainan, Anhui & 1.345 & 0.113 & MBC-S \\
\hline AH 22 & 2008 & Huainan, Anhui & 0.168 & 0.023 & MBC-S \\
\hline AH23 & 2008 & Wuhu, Anhui & 0.134 & 0.033 & MBC-S \\
\hline $\mathrm{AH} 24$ & 2008 & Wuhu, Anhui & 0.245 & 0.052 & MBC-S \\
\hline HB1 & 2007 & Xiaogan, Hubei & 1.505 & 0.206 & MBC-S \\
\hline HB2 & 2007 & Xiaogan, Hubei & 0.213 & 0.016 & MBC-S \\
\hline HB3 & 2007 & Xiaogan, Hubei & 0.031 & 0.019 & MBC-S \\
\hline HB4 & 2007 & Xiaogan, Hubei & 0.199 & 0.167 & MBC-S \\
\hline HB5 & 2007 & Xiaogan, Hubei & 0.122 & 0.112 & MBC-S \\
\hline HB6 & 2007 & Xiaogan, Hubei & 0.333 & 0.111 & MBC-S \\
\hline HB7 & 2007 & Xiaogan, Hubei & 0.174 & 0.022 & MBC-S \\
\hline HB8 & 2007 & Xiaogan, Hubei & 0.101 & 0.040 & MBC-S \\
\hline HB9 & 2007 & Xiaogan, Hubei & 0.190 & 0.016 & MBC-S \\
\hline HB10 & 2007 & Shiyan, Hubei & 0.143 & 0.017 & MBC-S \\
\hline HB12 & 2007 & Shiyan, Hubei & 0.063 & 0.237 & MBC-S \\
\hline HB13 & 2007 & Shiyan, Hubei & 0.533 & 0.015 & MBC-S \\
\hline HB14 & 2007 & Zhongxiang, Hubei & 0.088 & 0.020 & MBC-S \\
\hline HB15 & 2007 & Xiangfan, Hubei & 0.116 & 0.049 & MBC-S \\
\hline HB16 & 2007 & Xiangfan, Hubei & 0.317 & 0.067 & MBC-S \\
\hline HB17 & 2007 & Jingmen, Hubei & 0.147 & 0.025 & MBC-S \\
\hline HB18 & 2007 & jingmen, Hubei & 0.813 & 0.020 & MBC-S \\
\hline HB19 & 2007 & Qianjiang, Hubei & 0.163 & 0.018 & MBC-S \\
\hline \multirow[t]{2}{*}{ HB20 } & 2007 & Qianjiang, Hubei & 0.174 & 0.026 & MBC-S \\
\hline & & & & & (continued on next page) \\
\hline
\end{tabular}

${ }^{a} \mathrm{EC}_{50}=$ effective concentration that results in $50 \%$ mycelial growth inhibition.

b MBC-S and MBC-R indicate carbendazim (MBC)-sensitive and -resistant isolates, respectively. 
TABLE 1. (continued from preceding page)

\begin{tabular}{|c|c|c|c|c|c|}
\hline \multirow[b]{2}{*}{ Isolate } & \multirow[b]{2}{*}{ Year of isolation } & \multirow[b]{2}{*}{ Origin (city, province) } & \multicolumn{2}{|c|}{$\mathrm{EC}_{50}(\mu \mathrm{g} / \mathrm{ml})^{\mathrm{a}}$} & \multirow[b]{2}{*}{ Sensitivity to carbendazim ${ }^{\mathrm{b}}$} \\
\hline & & & Tebuconazole & Prochloraz & \\
\hline HB21 & 2007 & Wuchang, Hubei & 0.190 & 0.026 & MBC-S \\
\hline HB22 & 2007 & Wuchang, Hubei & 0.288 & 0.035 & MBC-S \\
\hline $\mathrm{HB} 23$ & 2007 & Wuchang, Hubei & 0.092 & 0.043 & MBC-S \\
\hline $\mathrm{HB} 24$ & 2007 & Wuhan, Hubei & 1.717 & 0.302 & MBC-S \\
\hline JX1 & 2007 & Jiujiang, Jiangxi & 0.248 & 0.056 & MBC-S \\
\hline JX2 & 2007 & Jiujiang, Jiangxi & 0.085 & 0.115 & MBC-S \\
\hline JX3 & 2007 & Jiujiang, Jiangxi & 2.079 & 0.376 & MBC-S \\
\hline JX4 & 2007 & Jiujiang, Jiangxi & 0.090 & 0.035 & MBC-S \\
\hline JX5 & 2007 & Jiujiang, Jiangxi & 0.086 & 0.055 & MBC-S \\
\hline JX6 & 2007 & Jiangxi & 0.130 & 0.094 & MBC-S \\
\hline JX7 & 2007 & De'an, Jiangxi & 0.093 & 0.050 & MBC-S \\
\hline JX8 & 2007 & De'an, Jiangxi & 0.111 & 0.050 & MBC-S \\
\hline JX10 & 2007 & Ruichang, Jiangxi & 0.249 & 0.047 & MBC-S \\
\hline $\mathrm{ZJ} 1$ & 2008 & Wenzhou, Zhejiang & 0.213 & 0.015 & MBC-S \\
\hline $\mathrm{ZJ} 2$ & 2008 & Wenzhou, Zhejiang & 0.097 & 0.007 & MBC-S \\
\hline $\mathrm{ZJ} 3$ & 2008 & Wenzhou, Zhejiang & 0.395 & 0.024 & MBC-S \\
\hline ZJ4 & 2008 & Wenzhou, Zhejiang & 0.087 & 0.003 & MBC-S \\
\hline $\mathrm{ZJ} 5$ & 2008 & Wenzhou, Zhejiang & 0.097 & 0.001 & MBC-S \\
\hline ZJ6 & 2008 & Fuyang, Zhejiang & 0.130 & 0.036 & MBC-S \\
\hline $\mathrm{ZJ} 7$ & 2008 & Fuyang, Zhejiang & 0.221 & 0.023 & MBC-S \\
\hline $\mathrm{ZJ} 8$ & 2008 & Hangzhou, Zhejiang & 0.328 & 0.032 & MBC-S \\
\hline ZJ9 & 2008 & Hangzhou, Zhejiang & 0.206 & 0.056 & MBC-S \\
\hline $\mathrm{ZJ} 10$ & 2008 & Hangzhou, Zhejiang & 0.089 & 0.002 & MBC-R \\
\hline ZJ11 & 2008 & Pinghu, Zhejiang & 0.896 & 0.285 & MBC-R \\
\hline $\mathrm{ZJ} 12$ & 2008 & Pinghu, Zhejiang & 1.230 & 0.153 & MBC-R \\
\hline ZJ13 & 2008 & Pinghu, Zhejiang & 0.097 & 0.005 & MBC-S \\
\hline ZJ14 & 2008 & Pinghu, Zhejiang & 0.174 & 0.024 & MBC-S \\
\hline GZ1 & 2007 & Guiyang, Guizhou & 0.174 & 0.008 & MBC-S \\
\hline GZ2 & 2007 & Tongren, Guizhou & 0.323 & 0.018 & MBC-S \\
\hline GZ3 & 2007 & Tongren, Guizhou & 0.164 & 0.024 & MBC-S \\
\hline GZ4 & 2007 & Tongren, Guizhou & 0.167 & 0.015 & MBC-S \\
\hline FJ1 & 2007 & Jianyang, Fujian & 0.145 & 0.002 & MBC-S \\
\hline $\mathrm{SC} 1$ & 2007 & Deyang, Sichuan & 0.670 & 0.022 & MBC-S \\
\hline $\mathrm{SC} 2$ & 2007 & Deyang, Sichuan & 0.108 & 0.032 & MBC-S \\
\hline $\mathrm{SC} 4$ & 2007 & Ya'an, Sichuan & 0.096 & 0.067 & MBC-S \\
\hline HE-5 & 2007 & Handan, Hebei & 0.211 & 0.423 & MBC-S \\
\hline HN6 & 2007 & Luohe, Henan & 0.150 & 0.024 & MBC-S \\
\hline HN11 & 2007 & Luohe, Henan & 0.042 & 0.003 & MBC-S \\
\hline HN13 & 2007 & Zhengzhou, Henan & 0.089 & 0.002 & MBC-S \\
\hline HN23 & 2007 & Jiaozuo, Henan & 0.089 & 0.009 & MBC-S \\
\hline SD2 & 2007 & Zaozhuang, Shandong & 0.111 & 0.022 & MBC-S \\
\hline SD3 & 2007 & Zaozhuang, Shandong & 0.347 & 0.280 & MBC-S \\
\hline SD5 & 2007 & Zaozhuang, Shandong & 0.494 & 0.031 & MBC-S \\
\hline HLJ3 & 2007 & Daqing, Heilongjiang & 0.187 & 0.002 & MBC-S \\
\hline HLJ6 & 2007 & Daqing, Heilongjiang & 0.010 & 0.018 & MBC-S \\
\hline HLJ7 & 2007 & Daqing, Heilongjiang & 0.065 & 0.002 & MBC-S \\
\hline HLJ8 & 2007 & Daqing, Heilongjiang & 0.137 & 0.014 & MBC-S \\
\hline NX4 & 2007 & Yinchuan, Ningxia & 0.073 & 0.015 & MBC-S \\
\hline SX1 & 2007 & Shangluo, Shanxi & 0.110 & 0.020 & MBC-S \\
\hline SX2 & 2007 & Shangluo, Shanxi & 0.667 & 0.246 & MBC-S \\
\hline \multicolumn{6}{|c|}{ F. graminearum } \\
\hline $\mathrm{AH} 2$ & 2008 & Chuzhou, Anhui & 0.021 & 0.009 & MBC-S \\
\hline AH18 & 2008 & Suzhou, Anhui & 0.562 & 0.073 & MBC-S \\
\hline HB11 & 2007 & Shiyan, Hubei & 0.700 & 0.025 & MBC-S \\
\hline JX9 & 2007 & Ruichang, Jiangxi & 0.082 & 0.033 & MBC-S \\
\hline $\mathrm{SC} 3$ & 2007 & Deyang, Sichuan & 0.443 & 0.013 & MBC-S \\
\hline HE-1 & 2007 & Handan, Hebei & 0.046 & 0.002 & MBC-S \\
\hline HE-2 & 2007 & Handan, Hebei & 0.516 & 0.021 & MBC-S \\
\hline HE-3 & 2007 & Handan, Hebei & 0.059 & 0.010 & MBC-S \\
\hline $\mathrm{HE}-4$ & 2007 & Handan, Hebei & 0.050 & 0.014 & MBC-S \\
\hline HN1 & 2008 & Luohe, Henan & 0.069 & 0.027 & MBC-S \\
\hline $\mathrm{HN} 2$ & 2008 & Luohe, Henan & 1.098 & 0.032 & MBC-S \\
\hline $\mathrm{HN} 3$ & 2008 & Luohe, Henan & 0.120 & 0.012 & MBC-S \\
\hline HN4 & 2008 & Luohe, Henan & 0.436 & 0.077 & MBC-S \\
\hline HN5 & 2008 & Luohe, Henan & 0.164 & 0.030 & MBC-S \\
\hline HN7 & 2008 & Luohe, Henan & 0.123 & 0.030 & MBC-S \\
\hline HN8 & 2008 & Luohe, Henan & 6.235 & 4.575 & MBC-S \\
\hline HN9 & 2008 & Luohe, Henan & 0.144 & 0.010 & MBC-S \\
\hline HN10 & 2008 & Luohe, Henan & 0.034 & 0.001 & MBC-S \\
\hline HN12 & 2008 & Luohe, Henan & 0.156 & 0.089 & MBC-S \\
\hline \multirow[t]{2}{*}{ HN14 } & 2008 & Luoyang, Henan & 0.103 & 0.014 & MBC-S \\
\hline & & & & & (continued on next page) \\
\hline
\end{tabular}


(approximately $100 \mathrm{mg}$ ) were ground with a motor-driven pestle in $100 \mu \mathrm{l}$ of TaKaRa RNAiso Reagent in a $1.5-\mathrm{ml}$ centrifuge tube for $1 \mathrm{~min}$; then, $900 \mu \mathrm{l}$ of RNAiso Reagent was added. After the tubes were kept at $22 \pm 2{ }^{\circ} \mathrm{C}$ (room temperature) for $5 \mathrm{~min}, 200 \mu \mathrm{l}$ of chloroform was added into each tube to emulsify. After incubation at room temperature for $5 \mathrm{~min}$, the tubes were spun for $15 \mathrm{~min}$ at $12,000 \mathrm{rpm}$. The supernatants were transferred into new tubes and an equal volume of isopropanol was added to precipitate the RNA. The tubes were kept at room temperature for $10 \mathrm{~min}$ before being spun at $10,000 \mathrm{rpm}$ for $15 \mathrm{~min}$. Finally, recovered RNA pellets were washed with $75 \%$ ethanol and suspended in $20 \mu \mathrm{l}$ of RNase-free water.
For each RNA sample, $4 \mu \mathrm{l}$ of RNA solution was used for reverse transcription using the oligo $(\mathrm{dT})_{18}$ primer with a RevertAid $\mathrm{H}$ Minus First Strand cDNA Synthesis kit (Fermentas Life Sciences, Burlington, Canada) according to the manufacturer's recommendations. Reverse-transcription PCRs with the primer pairs F51A-EX-F + F51A-EX-R and F51B-EX-F + F51B-EX-R (Table 2) were conducted to examine transcriptions of cyp51A and cyp $51 B$, respectively. Each primer pair spans one intron to identify amplification of possible contaminating genomic DNA. PCR amplifications were performed using the following parameters: initial preheat for $3 \mathrm{~min}$ at $95^{\circ} \mathrm{C}$; followed by 35 cycles of $94^{\circ} \mathrm{C}$ for $30 \mathrm{~s}, 53^{\circ} \mathrm{C}$ for $30 \mathrm{~s}$, and $72^{\circ} \mathrm{C}$ for $30 \mathrm{~s}$; and a final extension at $72^{\circ} \mathrm{C}$ for $5 \mathrm{~min}$.

TABLE 1. (continued from preceding page)

\begin{tabular}{|c|c|c|c|c|c|}
\hline \multirow[b]{2}{*}{ Isolate } & \multirow[b]{2}{*}{ Year of isolation } & \multirow[b]{2}{*}{ Origin (city, province) } & \multicolumn{2}{|c|}{$\mathrm{EC}_{50}(\mu \mathrm{g} / \mathrm{ml})^{\mathrm{a}}$} & \multirow[b]{2}{*}{ Sensitivity to carbendazim ${ }^{b}$} \\
\hline & & & Tebuconazole & Prochloraz & \\
\hline HN15 & 2008 & Luoyang, Henan & 0.036 & 0.024 & MBC-S \\
\hline HN16 & 2008 & Jiaozuo, Henan & 0.242 & 0.016 & MBC-S \\
\hline HN17 & 2008 & Jiaozuo, Henan & 0.356 & 0.019 & MBC-S \\
\hline HN18 & 2008 & Jiaozuo, Henan & 0.481 & 0.023 & MBC-S \\
\hline HN19 & 2008 & Jiaozuo, Henan & 0.231 & 0.036 & MBC-S \\
\hline HN20 & 2008 & Jiaozuo, Henan & 0.456 & 0.012 & MBC-S \\
\hline HN21 & 2008 & Jiaozuo, Henan & 0.295 & 0.029 & MBC-S \\
\hline $\mathrm{HN} 22$ & 2008 & Jiaozuo, Henan & 0.045 & 0.008 & MBC-S \\
\hline SD1 & 2007 & Zaozhuang, Shandong & 0.463 & 0.009 & MBC-S \\
\hline SD4 & 2007 & Zaozhuang, Shandong & 0.053 & 0.002 & MBC-S \\
\hline HLJ1 & 2007 & Ha'erbing, Heilongjiang & 0.097 & 0.011 & MBC-S \\
\hline HLJ2 & 2007 & Ha'erbing, Heilongjiang & 0.223 & 0.021 & MBC-S \\
\hline HLJ4 & 2007 & Daqing, Heilongjiang & 0.097 & 0.001 & MBC-S \\
\hline HLJ5 & 2007 & Daqing, Heilongjiang & 0.097 & 0.006 & MBC-S \\
\hline HLJ9 & 2007 & Daqing, Heilongjiang & 0.082 & 0.033 & MBC-S \\
\hline HLJ10 & 2007 & Daqing, Heilongjiang & 1.152 & 0.071 & MBC-S \\
\hline HLJ11 & 2007 & Daqing, Heilongjiang & 0.171 & 0.010 & MBC-S \\
\hline NX1 & 2007 & Yinchuan, Ningxia & 0.068 & 0.010 & MBC-S \\
\hline NX2 & 2007 & Yinchuan, Ningxia & 0.121 & 0.036 & MBC-S \\
\hline NX3 & 2007 & Yinchuan, Ningxia & 0.046 & 0.010 & MBC-S \\
\hline SX3 & 2007 & Shangluo, Shanxi & 0.181 & 0.032 & MBC-S \\
\hline
\end{tabular}

TABLE 2. List of polymerase chain reaction (PCR) primers used in this study

\begin{tabular}{|c|c|c|}
\hline Primer & Sequence $\left(5^{\prime}-3^{\prime}\right)$ & Relevant characteristics ${ }^{a}$ \\
\hline GzTri7f1 & GCTTTACGACTCCTCAACAATGG & PCR primer pairs used for the identification of $F$. asiaticum and $F$. graminearum isolates \\
\hline GzTri7r1 & AGAGCCCTGCGAAAG(C/T)ACTGGTGC & $\ldots$ \\
\hline$(\mathrm{AAC})_{5}$ & AACAACAACAACAAC & $\begin{array}{l}\text { Microsatellite primers for analysis of genetic variation in population of } F \text {. asiaticum and } \\
F \text {. graminearum }\end{array}$ \\
\hline$(\mathrm{GACA})_{4}$ & GACAGACAGACAGACA & $\ldots$ \\
\hline M13 & GAGGGTGGCGGTTCT & $\ldots$ \\
\hline F51A-F & TTCCAATCTCTTGTTTTGCGT & $\begin{array}{l}\text { PCR primers for amplification of full sequence of cyp } 51 A \text { gene from DMI-R and DMI-S } \\
\text { isolates of } F \text {. asiaticum and } F \text {. graminearum }\end{array}$ \\
\hline F51A-R & TCGGGATGCTAACACAACTT & $\ldots$ \\
\hline F51B-F & GGTCCGAAAAAAAGATGTTCG & $\begin{array}{l}\text { PCR primers for amplification of full sequence of cyp } 51 B \text { gene from DMI-R and DMI-S } \\
\text { isolates of } F \text {. asiaticum and } F \text {. graminearum }\end{array}$ \\
\hline F51B-R & ATCATTGCCGTCAGGCATAA & $\ldots$ \\
\hline F51C-F1 & AGCACGATGGAATCGCTCTA & $\begin{array}{l}\text { PCR primer pairs for amplification of cyp } 51 C \text { gene from DMI-R and DMI-S isolates of } \\
F \text {. asiaticum and } F \text {. graminearum }\end{array}$ \\
\hline F51C-R1 & GCTCGGTCTACACATCCATCA & $\ldots$ \\
\hline F51C-F2 & ATGGAATCGCTCTACGAGACT & $\ldots$ \\
\hline F51C-R2 & TCATTCTACTGTCTCGCGTCG & $\ldots$ \\
\hline F51C-F3 & TTTACGTTCAACGACCTGGA & $\ldots$ \\
\hline F51C-R3 & AGACGAAAGCAGTGTGTGGGA & $\ldots$ \\
\hline F51C-F4 & TCACAATCTACACAGCATCCG & $\ldots$ \\
\hline F51C-R4 & TCCTCGTACAGTTCCTGAACA & $\ldots$ \\
\hline F51C-F5 & TGGAATCGCTCTACGAGACTC & $\ldots$ \\
\hline F51C-R5 & AGCATGGTTTCGACGGAAGT & $\ldots$ \\
\hline F51A-EX-F & TGGACCCTTGTGGCTTCTTT & $\begin{array}{l}\text { PCR primers for analysis expression of cyp } 51 A \text { gene in DMI-R and DMI-S isolates of } \\
F \text {. asiaticum and } F \text {. graminearum }\end{array}$ \\
\hline F51A-EX-R & GCTTTTTGCGTAAGGCCAAA & $\ldots$ \\
\hline F51B-EX-F & TCAATGTCCTCAACCAGCTC & $\begin{array}{l}\text { PCR primers for analysis expression of cyp } 51 B \text { gene in DMI-R and DMI-S isolates of } \\
F \text {. asiaticum and F. graminearum }\end{array}$ \\
\hline F51B-EX-R & AGGATGAAGTCGTTTCCAGCA & $\ldots$ \\
\hline F-actin-F & ATCCACGTCACCACTTTCAA & PCR primers for amplification of the reference gene actin, in real-time PCR \\
\hline F-actin-R & TGCTTGGAGATCCACATTTG & $\ldots$ \\
\hline
\end{tabular}

a DMI-R and DMI-S = demethylation inhibitor-resistant and -sensitive, respectively. 
Expression levels of cyp51A and cyp51B in each DMI-R or DMI-S isolate were determined by real-time PCR assays. The real-time PCR amplifications were performed in a DNA Engine Opticons 4 System (MJ Research) using the SYBR Green I fluorescent dye detection. Amplifications were conducted in a $20-\mu l$ volume containing $10 \mu \mathrm{l}$ of iQ SYBR Green Supermix (BioRad Laboratories, Hercules, CA), $1 \mu$ l of reverse transcription product, and $0.5 \mu \mathrm{l}$ each of the forward and reverse primers (10 pmol each). There were two replicates for each sample. The real-time PCR amplifications were performed with the following parameters: an initial preheat at $95^{\circ} \mathrm{C}$ for $2 \mathrm{~min}$, followed by 35 cycles at $95^{\circ} \mathrm{C}$ for $15 \mathrm{~s}, 53^{\circ} \mathrm{C}$ for $20 \mathrm{~s}, 72^{\circ} \mathrm{C}$ for $40 \mathrm{~s}$, and $75^{\circ} \mathrm{C}$ for $3 \mathrm{~s}$ in order to detect and quantify the fluorescence at a temperature above the denaturation of primer-dimers. Once amplifications were completed, melting curves were obtained based on a standard protocol and used to identify PCR products. For each sample, PCR amplifications with primer pair F-actin-F + F-actin$\mathrm{R}$ (Table 2) for the quantification of expression of actin gene were performed as a reference because the actin is constitutively expressed (27). The real-time PCR conditions for the primers Factin-F + F-actin-R were the same as those of the primer pair F51A-EX-F + F51A-EX-R. The experiment was repeated twice. The expression of cyp51A and cyp51B in the fungicide-treated sample relative to that of untreated sample was calculated using the $2^{-\Delta \Delta \mathrm{Ct}}$ method (17) and the data were analyzed using analysis of variance of SAS (version 8.0; SAS Institute, Cary, NC).

\section{RESULTS}

Sensitivity of $F$. asiaticum and $F$. graminearum to $\mathrm{MBC}$. Previous studies showed that $\mathrm{MBC}$ at $10 \mu \mathrm{g} / \mathrm{ml}$ could be used as the threshold concentration for monitoring MBC resistance in $F$. graminearum (35). In this study, among the $118 \mathrm{~F}$. asiaticum and $41 F$. graminearum isolates tested, $109 \mathrm{~F}$. asiaticum isolates and all 41 F. graminearum isolates were unable to grow on PDA amended with $\mathrm{MBC}$ at $10 \mu \mathrm{g} / \mathrm{ml}$; therefore, they were designated

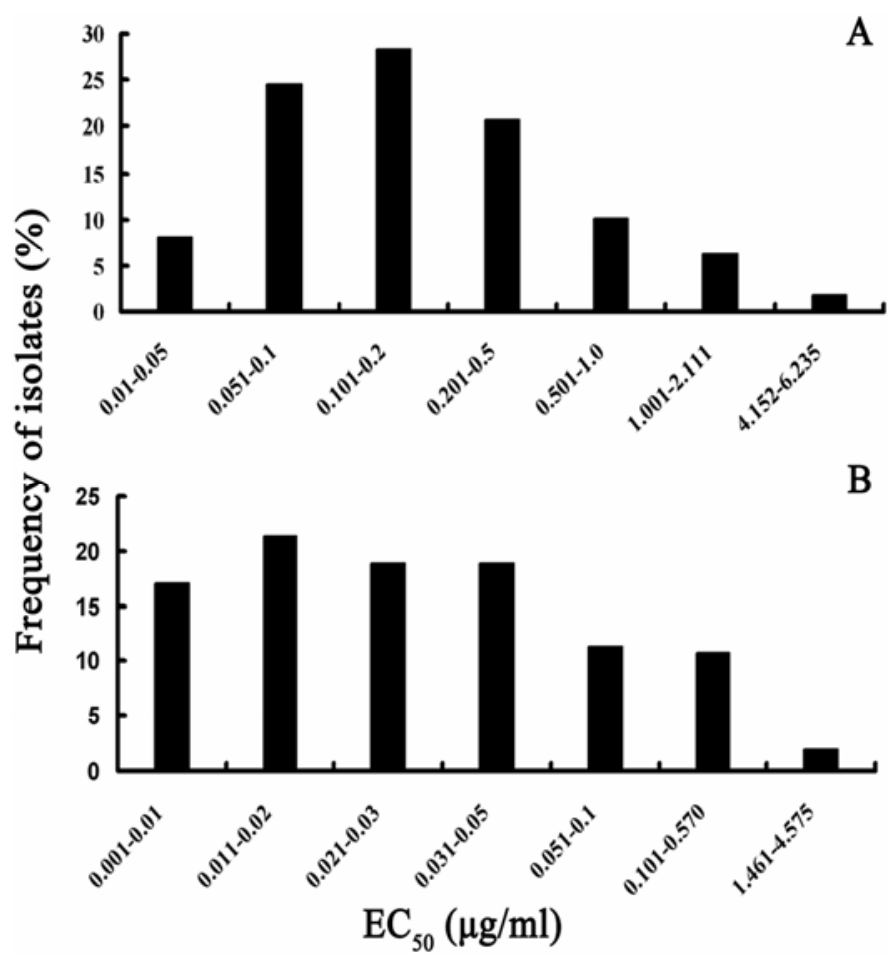

Fig. 1. Frequency distribution of effective concentration that results in $50 \%$ mycelial growth inhibition $\left(\mathrm{EC}_{50}\right)$ of $\mathbf{A}$, tebuconazole and $\mathbf{B}$, prochloraz for 118 Fusarium asiaticum isolates and $41 \mathrm{~F}$. graminearum isolates collected from different locations of China. as MBS-sensitive (MBC-S) isolates. Nine F. asiaticum isolates were able to grow on PDA amended with MBC at $100 \mu \mathrm{g} / \mathrm{ml}$ but not at $500 \mu \mathrm{g} / \mathrm{ml}$ within 5 days of incubation. These isolates were designated as MBC-R isolates (Table 1). All nine MBC-R isolates were collected from Zhejiang and Jiangsu provinces. MBC-R isolates were not detected from the samples collected from any of the other 12 provinces of China.

Sensitivity of $F$. asiaticum and $F$. graminearum to tebuconazole and prochloraz. The $\mathrm{EC}_{50}$ values for tebuconazole for the $F$. graminearum isolate $\mathrm{HN} 8$ and $F$. asiaticum isolates JS3 and JS6 were $6.24,4.152$, and $4.52 \mu \mathrm{g} / \mathrm{ml}$, respectively, which were significantly $(P<0.001, F=388.66)$ higher than those of the other 156 tested isolates. Thus, these three isolates were designated as DMI-R isolates and the rest were DMI-S. Except for these three isolates, the $\mathrm{EC}_{50}$ values of $40 \mathrm{~F}$. graminearum isolates to tebuconazole were $0.021-1.152 \mu \mathrm{g} / \mathrm{ml}$, with a mean of $0.248 \mu \mathrm{g} / \mathrm{ml}$. The $\mathrm{EC}_{50}$ values of the $116 \mathrm{~F}$. asiaticum isolates to tebuconazole were $0.010-2.111 \mu \mathrm{g} / \mathrm{ml}$, with a mean of $0.316 \mu \mathrm{g} / \mathrm{ml}$ (Table 1). Because the $F$. graminearum and $F$. asiaticum isolates were not significantly different $(P=0.9936)$ in their sensitivity to tebuconazole, they were combined for analysis of the frequency distribution of $\mathrm{EC}_{50}$ values to this fungicide (Fig. 1A). Inoculation tests showed that all three DMI-R isolates were able to cause disease on wheat heads treated with tebuconazole at $50 \mu \mathrm{g} / \mathrm{ml}$ but sensitive isolates HB3 and NX6 did not cause any disease.

Similar to tebuconazole, the three DMI-R isolates HN8, JS3, and JS6 were also resistant to prochloraz, with $\mathrm{EC}_{50}$ values of $4.575,1.467$, and $2.888 \mu \mathrm{g} / \mathrm{ml}$, respectively. The $\mathrm{EC}_{50}$ values were significantly $(P<0.001, F=678.68)$ higher than those of the remaining $156 \mathrm{~F}$. asiaticum and $F$. graminearum isolates, which indicated that there was a cross-resistance between tebuconazole and prochloraz. For the rest of the $156 \mathrm{~F}$. asiaticum and $F$. graminearum isolates, the $\mathrm{EC}_{50}$ values for prochloraz were 0.001 to $0.570 \mu \mathrm{g} / \mathrm{ml}$, with a mean of $0.050 \mu \mathrm{g} / \mathrm{ml}$. The frequency distribution of $\mathrm{EC}_{50}$ values of the $159 \mathrm{~F}$. asiaticum and $F$. graminearum isolates for prochloraz is presented in Figure 1B.

Genetic relationships among the MBC-R and DMI-R isolates. Three microsatellite primers generated a total of 22 polymorphic fragments from $39 \mathrm{~F}$. asiaticum and $F$. graminearum isolates. Examples of DNA fingerprint pattern generated by the primer $(\mathrm{AAC})_{5}$ are presented in Figure 2. UPGMA analysis showed that the nine MBC-R isolates were clustered into different groups. The three DMI-R isolates were also clustered into different groups (Fig. 3). These results indicated that MBC-R isolates and DMI-R isolates originated from different wild-type parents. Additionally, most $F$. asiaticum and $F$. graminearum isolates were clustered in separated groups (Fig. 3), which indicated that these microsatellite primers could generate informative markers for analysis of $F$. graminearum complex.

Comparison in DNA sequence of cyp51A and cyp51B genes from DMI-S and DMI-R isolates. Primer pair F51C-F1 + F51C$\mathrm{R} 1$ amplified a target fragment from each $F$. graminearum isolate but not from any F. asiaticum isolate tested; therefore, four other primer pairs based on the DNA sequence of $F$. graminearum cyp51C were designed (Table 2). However, these four primer pairs did not amplify any fragment from $F$. asiaticum. Thus, in this study, we only analyzed two cyp51 genes, cyp51A and cyp51B.

The DNA sequences of cyp51A and cyp $51 B$ from the F. graminearum isolate HN8 had 99.94 and $99.89 \%$ similarity, respectively, to those of the isolate PH-1, whose genome has been sequenced. The deduced amino acid sequence of cyp51A from the isolate HN8 was 64.66 and $59.31 \%$ to that of Aspergillus fumigatus (GenBank accession no. AF338659.1) and Penicillium digitatum (AB030178.1), respectively. The CYP51B from HN8 was also homologous to those from other phytopathogenic fungi. The deduced amino acid of cyp51B from HN8 showed similarities of 68.69 and $67.17 \%$ to that from Monilinia fructicola 
(AF470621.1) and B. cinerea (AF346594.1), respectively. The percentages of identity of the amino acid sequence were high enough to consider cyp $51 A$ and cyp $51 B$ to be members of the fungal cyp51 family (23) (Fig. 4).

Phylogenetic analysis of DNA sequence of cyp $51 \mathrm{~A}$ and $c y p 51 B$ showed that the $F$. asiaticum and $F$. graminearum isolates were clustered in two separate groups (Fig. 5A and B). In all, 69 nucleotide (nt) differences were observed in DNA sequence of the cyp $51 A$ between these two species. Among these $69 \mathrm{nt}$ differences, 53 did not cause any changes in deduced amino acids (silent substitutions) and the remaining 16 caused 16 amino acid differences that distinguished $F$. asiaticum from $F$. graminearum (Fig. 6, arrows). For DNA sequence of cyp51B gene, $4 \mathrm{nt}$ differences were observed between these two species; only $1 \mathrm{nt}$ caused one amino acid change at the codon position 30 whereas the other $3 \mathrm{nt}$ were silent substitutions. These results indicated that cyp51A could be an informative marker for the differentiation of phylogenetic species in $F$. graminearum complex.

Comparisons of the deduced amino acid sequence of CYP51A for the different isolates of $F$. asiaticum or $F$. graminearum showed that the three $F$. asiaticum isolates (JS3, JS6, and HB3) had three different amino acids and the three $F$. graminearum isolates (HN8, NX3, and PH-1) had five differences. However, the differences were not associated with DMI resistance (Fig. 6). Similar to those in the cyp51A gene, none of the different amino acids in $\operatorname{cyp} 51 B$ was found to be associated with DMI resistance.

Expression of cyp51 genes in DMI-R and DMI-S isolates. Reverse-transcription PCR with primer pair F51A-EX-F + F51AEX-R for cyp51A and F51B-EX-F + F51B-EX-R for cyp51B showed that both genes were transcribed in $F$. asiaticum and $F$. graminearum. Real-time PCR assays showed that the expression levels of both cyp51A and cyp51B were significantly $(P=0.0053$ for cyp51A; $P=0.0002$ for cyp51B) different among five tested isolates but were not associated with DMI resistance (Fig. 7A and B). When the isolates were treated with tebuconazole at $2.5 \mu \mathrm{g} / \mathrm{ml}$ $6 \mathrm{~h}$ before RNA extraction, expressions of cyp $51 \mathrm{~A}$ and cyp $51 \mathrm{~B}$ were higher than those of the isolates without fungicide treatment. The results indicated that expressions of both genes were induced greatly by tebuconazole.

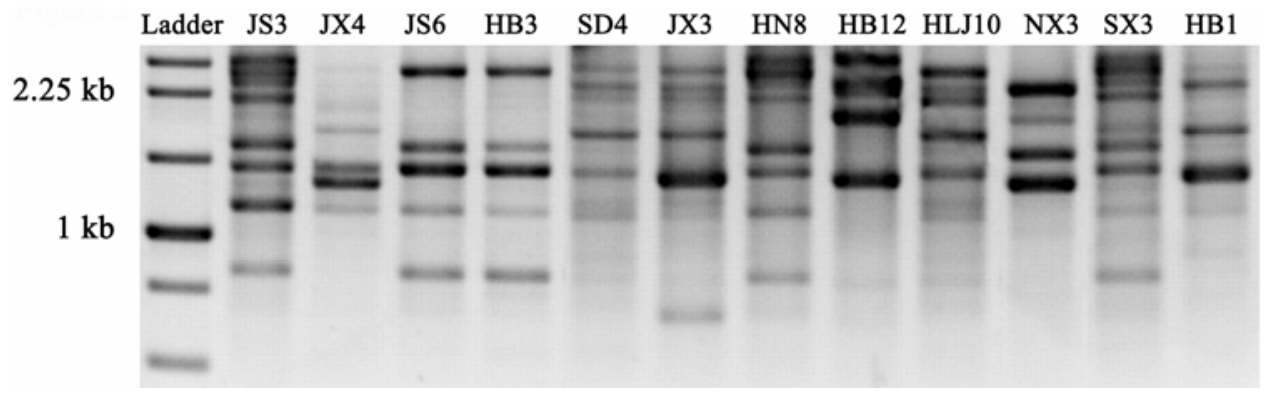

Fig. 2. Electrophoretic separation of DNA fingerprints of Fusarium asiaticum (JS3, JS6, JX3, JX4, HB1, HB3, and HB12) and F. graminearum isolates (SD4, HN8, HLJ10, SX3, and NX3) amplified by the microsatellite primer (AAC) .

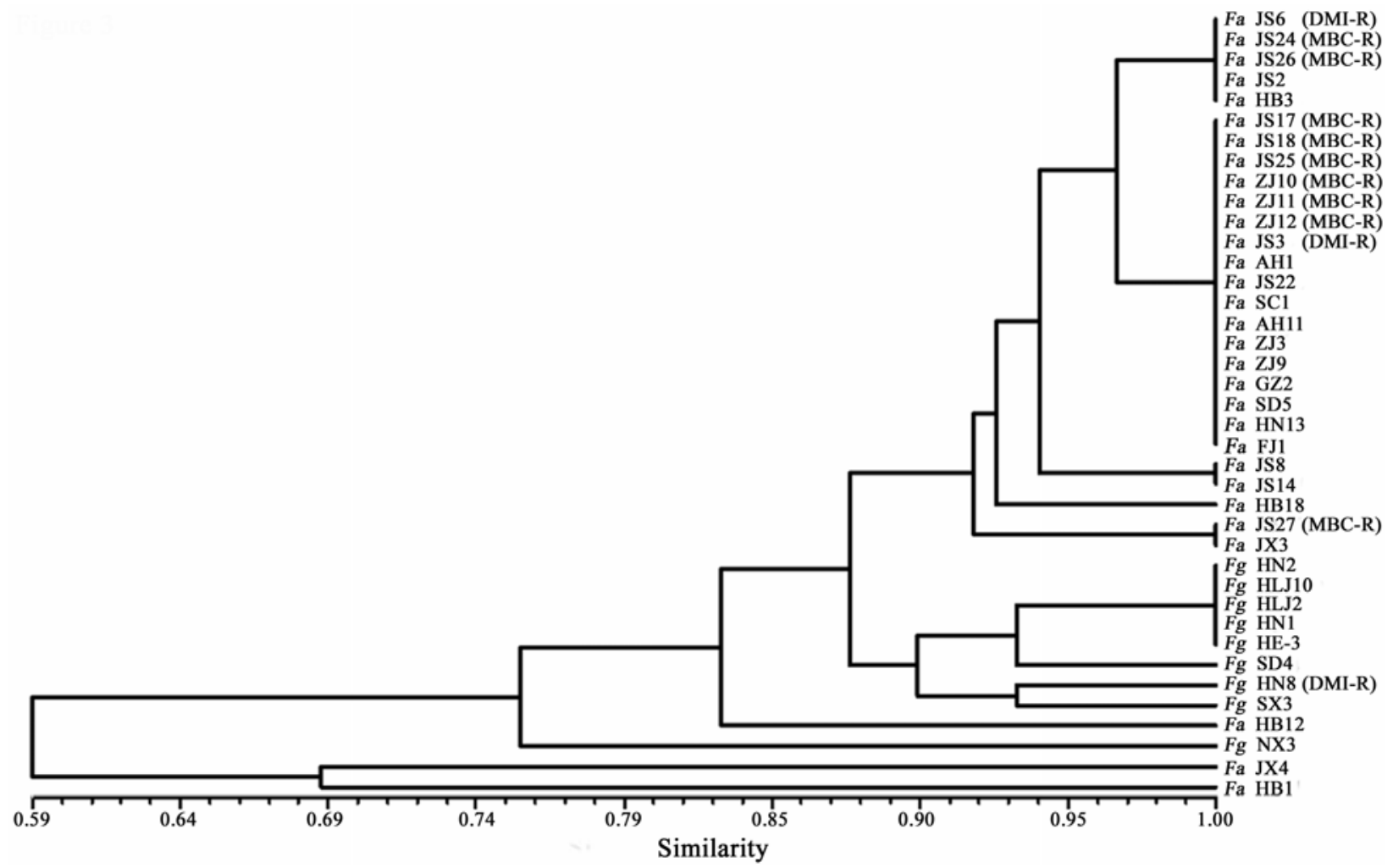

Fig. 3. Unweighted pair group method with arithmetic averages cluster analysis of microsatellite-primed polymerase chain reaction data for 30 Fusarium asiaticum and $9 \mathrm{~F}$. graminearum isolates, including 9 resistant to carbendazim (MBC-R) and 3 resistant to demethylation inhibitor (DMI-R) fungicides. The remaining 27 isolates were sensitive to both MBC and DMI fungicides. 


\section{DISCUSSION}

The inexpensive and effective benzimidazole fungicide MBC has been extensively applied for the control of FHB for more than two decades in China. In this study, among 159 isolates, 9 were resistant to MBC. All nine MBC-R isolates were sensitive to DMIs and vice versa; all three DMI-R isolates were sensitive to $\mathrm{MBC}$. The results indicated that alternative applications of benzimidazole and DMI fungicides would be effective in management of $\mathrm{MBC}$ resistance in FHB.

In Jiangsu province, MBC-R F. asiaticum was first detected in 1994 with a frequency of $0.29 \%$. In 2003, the frequency of resistant isolates increased to $18.69 \%$ (38). Since then, most growers used the mixture of $\mathrm{MBC}$, thiram, and triadimefon for control of FHB because the application of MBC alone was not effective. After the mixture was used for a few years, we found that the frequency of resistant isolates was decreased to $7.6 \%$ in 2008. In Zhejiang province, the frequency of MBC-R F. asiaticum was $0.25 \%$ in 1992 but increased to $25.60 \%$ in 1999 (38). In the past few years, many farmers did not grow wheat in this area. Subsequently, MBC was not used extensively any longer. In 2008, we tested 139 isolates collected from this area, and found that only three isolates $(2.15 \%)$ were resistant to MBC (unpublished data). These results suggested that the MBC-R $F$. asiaticum isolates might have lower fitness than sensitive ones in nature, and the mixture of $\mathrm{MBC}$ with another group of fungicides could delay the development of MBC resistance in F. asiaticum.

In this study, the DMI resistance was found from both $F$. asiaticum and $F$. graminearum but $\mathrm{MBC}$ resistance was found only from $F$. asiaticum, not from $F$. graminearum. The difference might be explained by the fact that $F$. asiaticum is predominant in

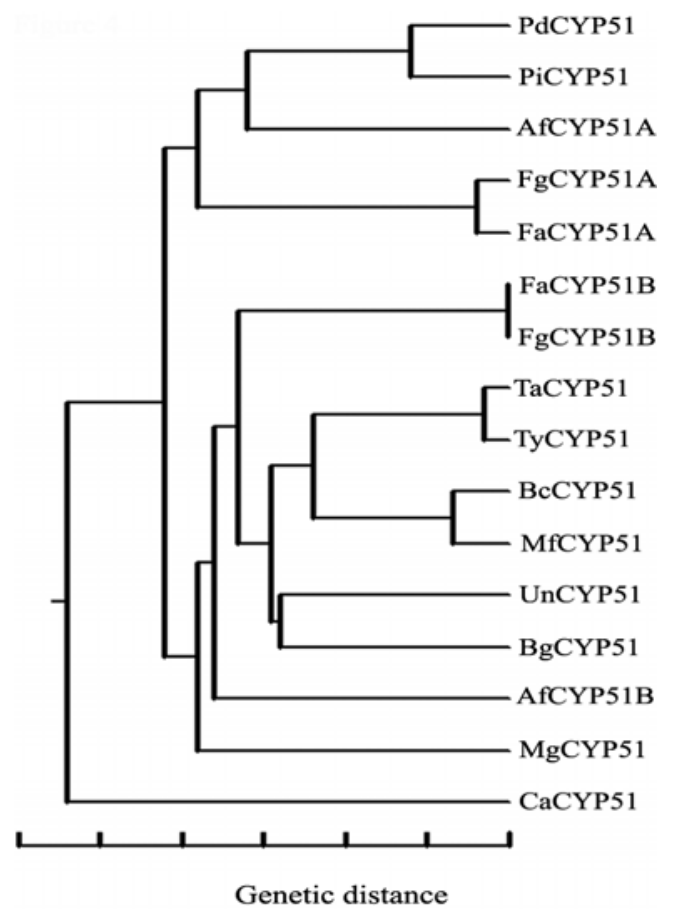

Fig. 4. Phylogenetic tree generated by the unweighted pair group method with arithmetic averages on the basis of deduced amino acid sequences of cyp51A (FgCYP51A) and cyp51B (FgCYP51B) from Fusarium graminearum isolate HN8, cyp51A (FaCYP51A) and cyp51B (FaCYP51B) from $F$. asiaticum isolate JS6, and those from Aspergillus fumigatus (AfCYP51A, GenBank accession no. AF338659.1), Penicillium digitatum (PdCYP51, AB030178.1), P. italicum (PiCYP51, Z49750.1), A. fumigatus (AfCYP51B, AF338660.1), Botrytis cinerea (BcCYP51, AF346594.1), Monilinia fructicola (MfCYP51, AF470621.1), Tapesia acuformis (TaCYP51, AF208657.1), T. yallundae (TyCYP51, AF208658.2), Blumeria graminis (BgCYP51, AF052515.1), Uncinula necator (UnCYP51, U83840.2), Mycosphaerella graminicola (MgCYP51, AF263470.1), and Candida albicans (CaCYP51, AB006854.1). warmer regions (such as Zhejiang and Jiangsu provinces), where FHB occurs frequently, and MBC had been used extensively in these regions. F. graminearum is more common than $F$. asiaticum in cooler regions where FHB is not very serious in most years (37). Additionally, although tebuconazole and prochloraz have never been used in the fields where samples were collected, another DMI fungicide, triadimefon, has been used for the control of wheat powdery mildew in most areas of China for more than 20 years. When farmers use triadimefon for the control of wheat powdery mildew, the fungicide may also have resulted in a selection pressure among FHB pathogens. Thus, it would not be surprising that three tebuconazole- and prochloraz-resistant isolates of $F$. asiaticum and $F$. graminearum were detected in this study.

Resistance to benzimidazole fungicides has been found in many fungal species. In most cases, resistance was correlated with point mutations in the $\beta$-tubulin gene, which results in altered amino acid sequences at the benzimidazole-binding site. In $F$. graminearum complex, however, the resistant and sensitive isolates had identical deduced amino acid sequence of $\beta$-tubulin genes (5). Additionally, Kawchuk et al. (12) reported that the amino acid sequences of the $\beta$-tubulin genes from several thiabendazole-resistant and -sensitive isolates of Gibberella pulicaris were also identical. Linkage analysis confirmed that the $\beta$-tubulin gene was not linked to thiabendazole resistance. These results indicated that other mechanisms than mutation in the $\beta$-tubulin should be responsible for the benzimidazole resistance in $\mathrm{Fu}$ sarium spp. More recently, when Chen et al. (6) analyzed a second $\beta$-tubulin gene (tub2) in F. graminearum complex, they found that MBC-R isolates had a point mutation at codon 167, resulting in a Phe replaced by Tyr (F167Y), or a point mutation at the codon position 198, resulting in a Glu replaced by Gln (E198Q). In this study, the point mutations F167Y and E198Q were also detected in five and four MBC-R isolates, respectively.

Our results showed that $F$. asiaticum and $F$. graminearum have homologous cyp51 genes. The presence of different cyp51 genes in a phytopathogenic fungus is not common but has been reported from several Aspergillus spp. (23). In A. fumigatus, the cyp51A disrupted mutants were 17 - to 40 -fold more sensitive than the wild-type parents but they were morphologically indistinguishable from the wild-type parents. The results indicated that cyp51A was associated with DMI sensitivity in A. fumigatus but it was not essential for viability (24). Interestingly, the disruption of cyp $51 \mathrm{~A}$
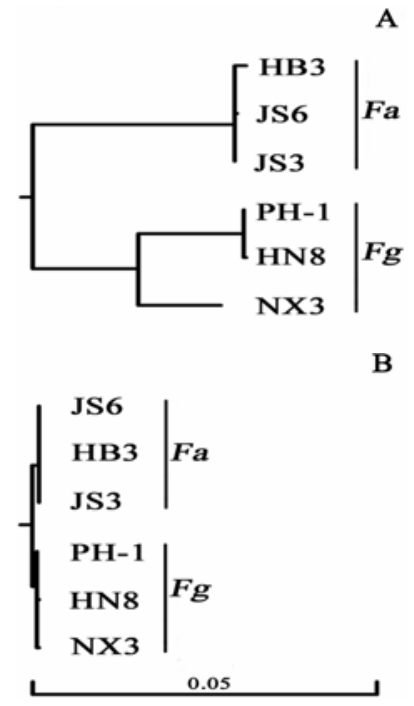

Fig. 5. Phylogenetic tree generated by the neighbor-joining method on the basis of DNA sequences of A, cyp51A and B, cyp $51 B$ from the Fusarium asiaticum $(F a)$ isolates JS3, JS6, and HB3 and $F$. graminearum $(F g)$ isolates HN8, NX3, and PH-1. Bar indicates 0.05 substitutions per nucleotide position. 
did not change the expression level of cyp51B. Disruption of cyp $51 B$ showed that this gene was related to growth rate and shape maintenance but its role in azole susceptibility remains unclear (2). In this study, we found that both $F$. asiaticum and $F$. graminearum have homologous cyp51 genes but the functions of these homologous cyp51 genes are not clear. It would be interesting to construct cyp51A, cyp51B, or cyp51C disruption mutants for functional analysis of these genes. Saccharomyces cerevisiae has only one cyp51 gene, and disruption of cyp51 gene in this fungus has been described as lethal (3). F. asiaticum and $F$. graminearum have three homologous cyp 51 genes; to analyze the function of each gene, we constructed disruptants for each cyp51 gene. Our preliminary results indicated that none of the proteins are individually essential for $F$. asiaticum and $F$. graminearum viability; however, the cyp51A and cyp51B disruption mutants showed different sensitivity patterns to different DMI fungicides.
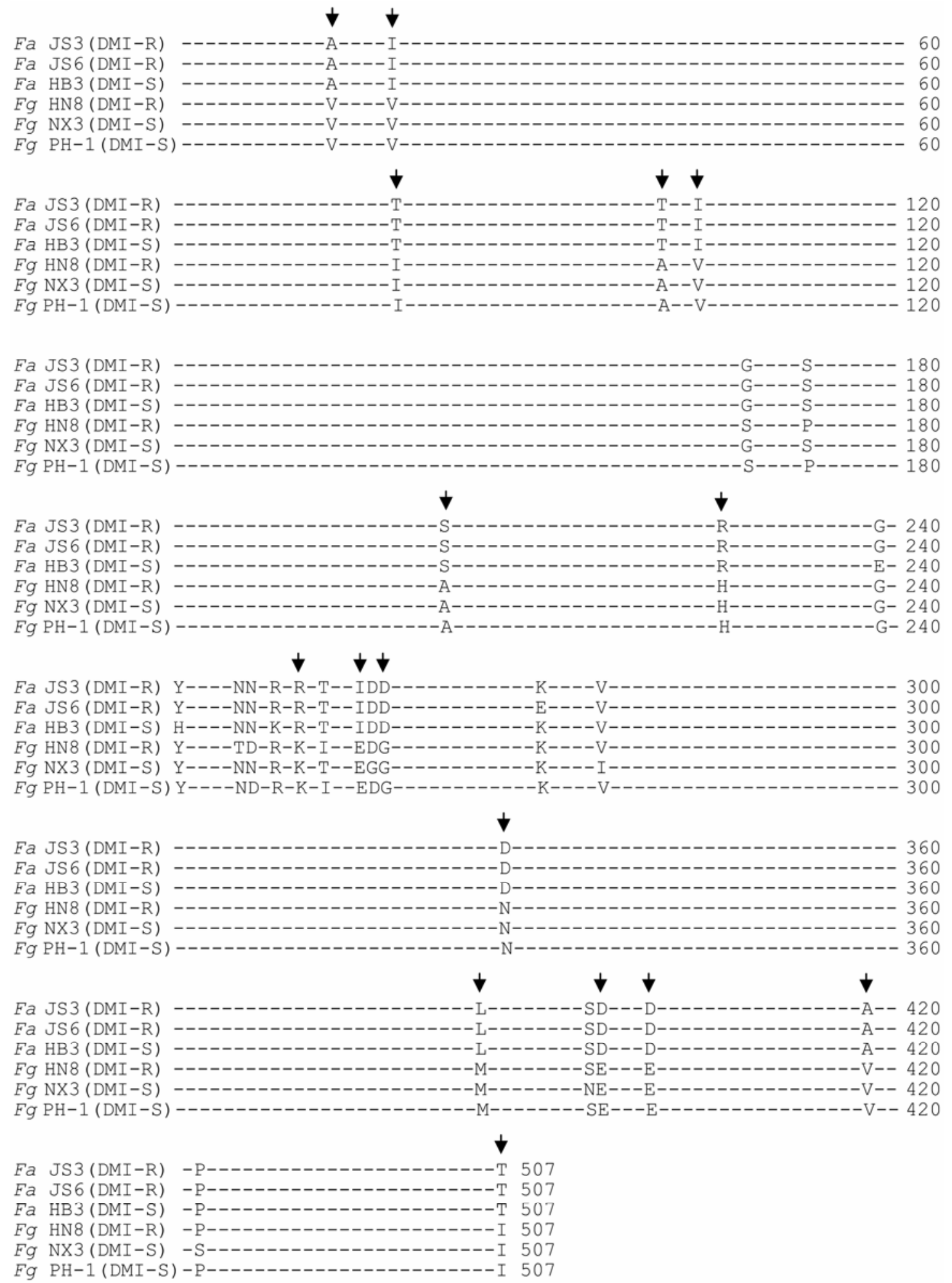

Fig. 6. Alignment of deduced amino acid of cyp51A from Fusarium asiaticum isolates JS3, JS6, and HB3 and F. graminearum isolates HN8, NX3, and PH-1. The JS3, JS6, and HN8 were demethylation inhibitor-resistant (DMI-R) isolates, and the HB3, NX6, and PH-1 were DMI-sensitive (DMI-S). Identical residues are marked by short dash. Different residues between $F$. asiaticum and $F$. graminearum are indicated by short arrows. 
The cyp51A disruption mutants increased sensitivity significantly to triadimefon and propiconazole but not to tebuconazole and prochloraz (X. Liu and Z. Ma, unpublished data). Thus, it is possible that the different DMI fungicides may target different CYP51 proteins in $F$. asiaticum and $F$. graminearum. These results are in agreement with a previous finding that $F$. graminearum isolates do not show cross-resistance to some of the DMI fungicides $(8,13)$.

In this study, we observed that tebuconazole at $5.6 \mu \mathrm{g} / \mathrm{ml}$ could completely inhibit mycelial growth of DMI-S isolates within 5 days of incubation. However, all tested DMI-S isolates could grow at this concentration after 10 days of incubation. This phenomenon is consistent with the finding that expressions of both cyp $51 A$ and $-B$ genes were induced greatly by the tebuconazole. The DMIs are fungistatic but do not kill cells. When tebuconazole induces cyp51 expression for a period of time, more target CYP51 proteins are translated (30). Therefore, mycelial growth can occur after a few days of incubation on PDA amended with tebuconazole.

Point mutation in cyp51 and overexpression of the gene are the common mechanisms of DMI resistance in fungi. In this study, when the DNA sequences of cyp51A and cyp51B from DMI-S isolates and those from DMI-R isolates were compared, we did not observe any changes associated with DMI resistance. Realtime PCR assays showed that DMI resistance also was not related with levels of cyp51A or cyp51B expression. Fungicide sensitivity tests showed that although DMI-R isolates were sensitive to $\mathrm{MBC}$, they showed resistance to iprodione, azoxystrobin, and fengmycin (a lipopeptide produced by Bacillus subtilis) (unpublished data). These results indicated that $\mathrm{ABC}$ transporters might be involved in the resistance of $F$. asiaticum and $F$. graminearum

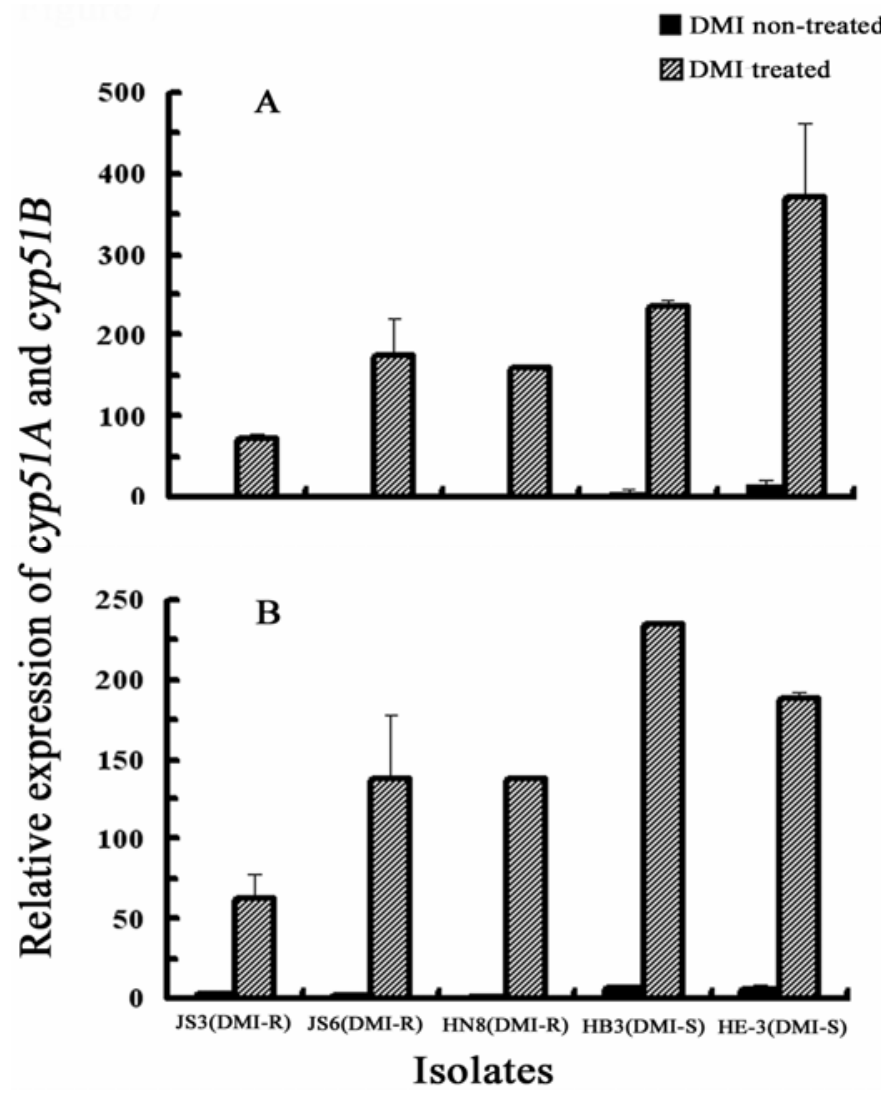

Fig. 7. Relative expression of A, cyp51A and $\mathbf{B}$, cyp51B in the demethylation inhibitor-resistant (DMI-R) isolates JS3, JS6, and HN8 and the DMI-sensitive (DMI-S) isolates HB3 and HE-3 of Fusarium spp. The relative expression of cyp $51 A$ and cyp $51 B$ is the relative amount of each gene mRNA in isolate JS6 without tebuconazole treatment, respectively. Line bars in each column denote standard errors of two experiments. to DMI. The search for $\mathrm{ABC}$ transporter genes in $F$. graminearum genome showed that there are at least 21 putative ABC transporters existing in this fungal species. Thus, it would be interesting to investigate the roles of these $\mathrm{ABC}$ transporters in DMI resistance in FHB pathogens.

Phylogenetic analysis of DNA sequences (16.3-kb) of 13 genes, including $\alpha$-tubulin, $\beta$-tubulin, elongation factor $1 \alpha$, histone $\mathrm{H} 3$, mating-type locus, reductase, ammonium ligase, phosphate permease, and trichothecene 3-O-acetyltransferase, could differentiate the two genetically related phylogenetic species $F$. asiaticum and $F$. graminearum (32). In this study, we found that $F$. asiaticum could be differentiated from $F$. graminearum based on the DNA sequences of cyp51A (Fig. 6). In Botrytis cinerea, the HydR1 strains are resistant naturally to the hydroxyanilide fungicide, fenhexamid. Phylogenetic analysis of the DNA sequence of cyp51 could distinguish HydR1 from non-HydR1 strains (1). The results indicated that cyp51 genes would be informative markers for analysis of population structure of some phytopathogenic fungi.

\section{ACKNOWLEDGMENTS}

The research was supported by the Special Program for Agricultural Research (nyhyzx07-048), the 863 program (2007AA10Z422), and the grant MATS from Department of Agriculture to Z. Ma.

\section{LITERATURE CITED}

1. Albertin, C., Thebaudm, G., Fournier, E., and Leroux, P. 2002. Eburicol $14 \alpha$-demethylase gene (CYP51) polymorphism and speciation in Botrytis cinerea. Mycol. Res. 106:1171-1178.

2. Alcazar-Fuoli, L., Rodriguez-Tudela, J. L., and Mellado, E. 2008. Antifungal drug resistance in molds: Clinical and microbiological factors. Curr. Fungal Infect. Rep. 2:36-42.

3. Bard, M., Lees, N. D., Turi, T., Craft, D., Cofrin, L., Barbuch, R., Koegel, C., and Loper, J. C. 1993. Sterol synthesis and viability of erg11 (cytochrome P450 lanosterol demethylase) mutations in Saccharomyces cerevisiae and Candida albicans. Lipids 28:963-967.

4. Brent, K. J. 1995. Fungicide Resistance in Crop Pathogens, How Can it be Managed. Global Crop Protection Federation, Brussels.

5. Chen, C., Wang, J., Luo, Q., Yuan, S., and Zhou, M. 2007. Characterization and fitness of carbendazim-resistant strains of Fusarium graminearum (wheat scab). Pest Manage. Sci. 63:1201-1207.

6. Chen, C., Yu J., Bi, C., and Zhou, M. 2008. Identification of point mutations in beta-tubulin 2 gene associated with $\mathrm{MBC}$ resistance in Gibberella zeae. Chem. Control Plant Dis. China 6:110.

7. Chen, H., Wang, G., and Liang, X. 1982. Study of Fusarium species on wheat and barley in Zhejiang and their pathogenicity. Acta Phytopathol. Sin. 12:1-12.

8. Cools, H. J., and Fraaije, B. A. 2008. Are azole fungicides losing ground against Septoria wheat disease? Resistance mechanisms in Mycosphaerella graminicola. Pest Manage. Sci. 64:681-684.

9. Delye, C., Bousset, L., and Corio-Costet, M. F. 1998. PCR cloning and detection of point mutations in the eburicol 14a-demethylase (CYP51) gene from Erysiphe graminis f. sp. hordei, a "recalcitrant" fungus. Curr. Genet. 34:399-403.

10. de Waard, M. A., Andrade, A. C., Hayashi, K., Schoonbeek, H., Stergiopoulos, I., and Zwiers, L. 2006. Impact of fungal drug transporters on fungicide sensitivity, multidrug resistance and virulence. Pest Manage. Sci. 62:195-207.

11. Donnell, K. O., Ward, T. J., Geiser, D. M., Kistler, H. C., and Aokid, T. 2004. Genealogical concordance between the mating type locus and seven other nuclear genes supports formal recognition of nine phylogenetically distinct species within the Fusarium graminearum clade. Fungal Genet. Biol. 41:600-623.

12. Kawchuk, L. M., Hutchison, L. J., Verhaeghe, C. A., Lynch, D. R., Bains, P. S., and Holley, J. D. 2002. Isolation of the $\beta$-tubulin gene and characterization of thiabendazole resistance in Gibberella pulicaris. Can. J. Plant Pathol. 24:233-238.

13. Klix, M. B., Verreet, J., and Beyer, M. 2007. Comparison of the declining triazole sensitivity of Gibberella zeae and increased sensitivity achieved by advances in triazole fungicide development. Crop Prot. 26:683-690.

14. Lee, T., Oh, D., Kim, H., Lee, J., Kim, Y., Yun, S., and Lee, Y. 2001. Identification of deoxynivalenol- and nivalenol-producing chemotypes of Gibberella zeae by using PCR. Appl. Environ. Microbiol. 67:2966-2972. 
15. Leroux, P., Albertini, C., Gautier, A., Gredt, M., and Walker, A. S. 2007. Mutations in the CYP51 gene correlated with changes in sensitivity to sterol 14 alpha-demethylation inhibitors in field isolates of Mycosphaerella graminicola. Pest Manage. Sci. 63:688-698.

16. Leroux, P., Chapeland, F., Desbrosses, D., and Gredt, M. 1999. Patterns of cross resistance to fungicides in Botryotinia fuckeliana (Botrytis cinerea) isolates from French vineyards. Crop Prot. 18:687-697.

17. Livak, K. J., and Schmittgen, T. D. 2001. Analysis of relative gene expression data using real-time quantitative PCR and the $2^{-\Delta \Delta \mathrm{Ct}}$ method. Methods 25:402-408.

18. Luo, C. X., and Schnabel, G. 2007. The cytochrome P450 lanosterol 14 alpha-demethylase gene is a demethylation inhibitor fungicide resistance determinant in Monilinia fructicola field isolates from Georgia. Appl. Environ. Microbiol. 74:359-366.

19. Ma, Z., Luo, Y., and Michailides, T. J. 2004. Spatiotemporal changes in the population structure of Botryosphaeria dothidea from California pistachio orchards. Phytopathology 94:326-332.

20. Ma, Z., and Michailides, T. J. 2005. Advances in understanding molecular mechanisms of fungicide resistance and molecular detection of resistant genotypes in phytopathogenic fungi. Crop Prot. 24:853-863.

21. Ma, Z., and Michailides T. J. 2005. Genetic population structure of Botrytis cinerea from different hosts in California. Plant Dis. 89:10831089.

22. Ma, Z. Proffer, T. J., Jacobs, J. L., and Sundin, G. W. 2006. Overexpression of the $14 \alpha$-demethylase target gene (CYP51) mediates fungicide resistance in Blumeriella jaapii. Appl. Environ. Microbiol. 72:2581-2585.

23. Mellado, E. Diaz-Guerra, T. M., Cuenca-Estrella, M., and RodriguezTudela, J. L. 2001. Identification of two different 14-asterol demethylaserelated genes (cyp51A and cyp51B) in Aspergillus fumigatus and other Aspergillus species. J. Clin. Microbiol. 39:2431-2438.

24. Mellado, E., Garcia-Effron, G., Buitrago, M. J., Alcazar-Fuoli, L., Cuenca-Estrella, M., and Rodriguez-Tudela, J. L. 2005. Targeted gene disruption of the $14 \alpha$-sterol demethylase (cyp51A) in Aspergillus fumigatus and its role in azole drug susceptibility. J. Clin. Microbiol. 49:2536-2538.

25. Mesterhazy, A., Bartok, T., and Lamper, C. 2003. Influence of wheat cultivar, species of Fusarium, and isolate aggressiveness on the efficiency of fungicides for control of Fusarium head blight. Plant Dis. 87:11071115 .

26. Muellenborn, C., Steiner, U., Ludwig, M., and Oerke, E. 2008. Effect of fungicides on the complex of Fusarium species and saprophytic fungi colonizing wheat kernels. Eur. J. Plant Pathol. 120:157-166.
27. Nicot, N., Hausman, J. F., Hoffmann, L., and Evers, D. 2005 Housekeeping gene selection for real-time RT-PCR normalization in potato during biotic and abiotic stress. J. Exp. Bot. 421:2907-2914.

28. Nisessen, L. 2007. PCR-based diagnosis and quantification of mycotoxin producing fungi. Int. J. Food Microbiol. 19:38-46.

29. O'Donnell, K., Ward, T. J., Geiser, D. M., Kistler, H. C., and Aoki, T. 2004. Genealogical concordance between mating type locus and seven other nuclear genes supports formal recognition of nine phylogenetically distinct species within the Fusarium graminearum clade. Fungal Genet. Biol. 41:600-623.

30. Oliver, B. G., Song, J. L., Choiniere, J. H., and White, T. C. 2007. cisActing elements within the Candida albicans ERG11 promoter mediate the azole response through transcription factor Upc2p. Eukaryot. Cell 12:2231-2239.

31. Schnabel, G., and Jones, A. L. 2001. The 14 $\alpha$-demethylase (CYP51A) gene is overexpressed in Venturia inaequalis strains resistant to myclobutanil. Phytopathology 91:102-110.

32. Starkey, D. E., Ward, T. J., Aoki, T., Gale, L. R., Kistler, H. C., Geiser, D. M., Suga, H., Tóth, B., Varga, J., and O'Donnel, K. 2007. Global molecular surveillance reveals novel Fusarium head blight species and trichothecene toxin diversity. Fungal Genet. Biol. 44:1191-1204.

33. Suga, H., Karugia, G. W., Ward, T., Gale, L. R., Tomimura, K., Nakajima, T., Miyasaka, A., Koizumi, S., Kageyama, K., and Hyakumachi, M. 2008. Molecular characterization of the Fusarium graminearum species complex in Japan. Phytopathology 98:159-166.

34. Tóth, B., Mesterházy, Á., Horváth, Z., Bartók, T., Varga, M., and Varga, J. 2005. Genetic variability of central European isolates of the Fusarium graminearum species complex. Eur. J. Plant Pathol. 113:35-45.

35. Wang, J., and Zhou, M. 2002. Monitoring and management of MBC resistance in Gibberella zeae. J. Nanjing Agric. Univ. 25:43-47.

36. Xu, X. M., Parry, D. W., Nicholson, P., Thomsett,, M. A, Simpson, D., Edwards, S. G., Cooke, B. M., Doohan, F. M., Monaghan, S., Moretti, A., Tocco, G., Mule, G., Hornok, L., Béki, E., Tatnell, J., and Ritieni, A. 2008. Within-field variability of Fusarium head blight pathogens and their associated mycotoxins. Eur. J. Plant Pathol. 120:21-34.

37. Zhang, J. B., Li, H. P., Dang, F. J., Qu, B., Xu, Y. B., Zhao, C.S., and Liao, Y. C. 2007. Determination of the trichothecene mycotoxin chemotypes and associated geographical distribution and phylogenetic species of the Fusarium graminearum clade from China. Mycol. Res. 111:967-975.

38. Zhou, M., and Wang, J. 2003. Dynamics of carbendazim-resistant population of Gibberella zeae on wheat in China. Page 6 in: Proc. Annu. Meet. East China Soc. Plant Pathol. Nanjing, China. 